\title{
Can the Evolution of Plant Defense Lead to Plant-Herbivore Mutualism?
}

Claire de Mazancourt (c.mazancourt@ic.ac.uk)

Michel Loreau (loreau@ens.fr)

Ulf Dieckmann (dieckman@iiasa.ac.at)

\section{Approved by}

Arne Jernelöv (jernelov@iiasa.ac.at)

Acting Director, IIASA

October 2001 


\section{IIASA STUDIES IN ADAPTIVE DYNAMICS NO. 56}

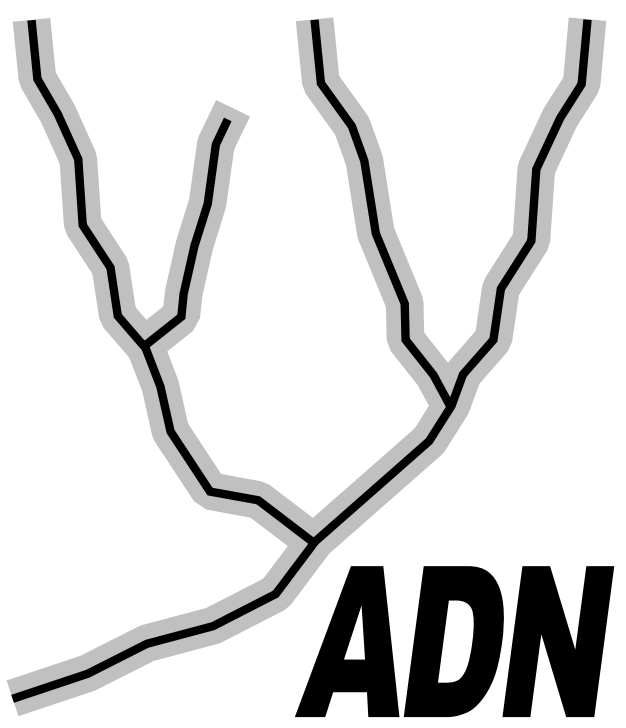

The Adaptive Dynamics Network at IIASA fosters the development of new mathematical and conceptual techniques for understanding the evolution of complex adaptive systems.

Focusing on these long-term implications of adaptive processes in systems of limited growth, the Adaptive Dynamics Network brings together scientists and institutions from around the world with IIASA acting as the central node.

Scientific progress within the network is reported in the IIASA Studies in Adaptive Dynamics series.

\section{THE ADAPTIVE DYNAMICS NETWORK}

The pivotal role of evolutionary theory in life sciences derives from its capability to provide causal explanations for phenomena that are highly improbable in the physicochemical sense. Yet, until recently, many facts in biology could not be accounted for in the light of evolution. Just as physicists for a long time ignored the presence of chaos, these phenomena were basically not perceived by biologists.

Two examples illustrate this assertion. Although Darwin's publication of "The Origin of Species" sparked off the whole evolutionary revolution, oddly enough, the population genetic framework underlying the modern synthesis holds no clues to speciation events. A second illustration is the more recently appreciated issue of jump increases in biological complexity that result from the aggregation of individuals into mutualistic wholes.

These and many more problems possess a common source: the interactions of individuals are bound to change the environments these individuals live in. By closing the feedback loop in the evolutionary explanation, a new mathematical theory of the evolution of complex adaptive systems arises. It is this general theoretical option that lies at the core of the emerging field of adaptive dynamics. In consequence a major promise of adaptive dynamics studies is to elucidate the long-term effects of the interactions between ecological and evolutionary processes.

A commitment to interfacing the theory with empirical applications is necessary both for validation and for management problems. For example, empirical evidence indicates that to control pests and diseases or to achieve sustainable harvesting of renewable resources evolutionary deliberation is already crucial on the time scale of two decades.

The Adaptive Dynamics Network has as its primary objective the development of mathematical tools for the analysis of adaptive systems inside and outside the biological realm. 


\section{IIASA STUDIES IN ADAPTIVE DYNAMICS}

No. 1 Metz JAJ, Geritz SAH, Meszéna G, Jacobs FJA, van Heerwaarden JS: Adaptive Dynamics: A Geometrical Study of the Consequences of Nearly Faithful Reproduction.

IIASA Working Paper WP-95-099.

In: van Strien SJ, Verduyn Lunel SM (eds.): Stochastic and Spatial Structures of Dynamical Systems, Proceedings of the Royal Dutch Academy of Science (KNAW Verhandelingen), North Holland, Amsterdam, pp. 183-231 (1996).

No. 2 Dieckmann U, Law R:

The Dynamical Theory of Coevolution: A Derivation from Stochastic

Ecological Processes.

IIASA Working Paper WP-96-001.

Journal of Mathematical Biology (1996) 34, 579-612.

No. 3 Dieckmann U, Marrow P, Law R:

Evolutionary Cycling of Predator-Prey Interactions: Population Dynamics and the Red Queen.

Journal of Theoretical Biology (1995) 176, 91-102.

No. 4 Marrow P, Dieckmann U, Law R:

Evolutionary Dynamics of Predator-Prey Systems: An Ecological

Perspective.

IIASA Working Paper WP-96-002.

Journal of Mathematical Biology (1996) 34, 556-578.

No. 5 Law R, Marrow P, Dieckmann U:

On Evolution under Asymmetric Competition.

IIASA Working Paper WP-96-003.

Evolutionary Ecology (1997) 11, 485-501.

No. 6 Metz JAJ, Mylius SD, Diekmann O:

When Does Evolution Optimise? On the Relation between Types of Density

Dependence and Evolutionarily Stable Life History Parameters.

IIASA Working Paper WP-96-004.

No. 7 Ferrière R, Gatto M:

Lyapunov Exponents and the Mathematics of Invasion in Oscillatory or Chaotic Populations.

Theoretical Population Biology (1995) 48, 126-171. 
No. 8 Ferrière R, Fox GA:

Chaos and Evolution.

Trends in Ecology and Evolution (1995) 10, 480-485.

No. 9 Ferrière R, Michod RE:

The Evolution of Cooperation in Spatially Heterogeneous Populations.

IIASA Working Paper WP-96-029.

American Naturalist (1996) 147, 692-717.

No. 10 Van Dooren TJM, Metz JAJ:

Delayed Maturation in Temporally Structured Populations with Non-Equilibrium Dynamics.

IIASA Working Paper WP-96-070.

Journal of Evolutionary Biology (1998) 11, 41-62.

No. 11 Geritz SAH, Metz JAJ, Kisdi É, Meszéna G:

The Dynamics of Adaptation and Evolutionary Branching.

IIASA Working Paper WP-96-077.

Physical Review Letters (1997) 78, 2024-2027.

No. 12 Geritz SAH, Kisdi É, Meszéna G, Metz JAJ:

Evolutionarily Singular Strategies and the Adaptive Growth and Branching of the Evolutionary Tree.

IIASA Working Paper WP-96-114.

Evolutionary Ecology (1998) 12, 35-57.

No. 13 Heino M, Metz JAJ, Kaitala V:

Evolution of Mixed Maturation Strategies in Semelparous Life-Histories: the Crucial Role of Dimensionality of Feedback Environment.

IIASA Working Paper WP-96-126.

Philosophical Transactions of the Royal Society of London Series B (1997) 352, $1647-$ 1655.

No. 14 Dieckmann U:

Can Adaptive Dynamics Invade?

IIASA Working Paper WP-96-152.

Trends in Ecology and Evolution (1997) 12, 128-131.

No. 15 Meszéna G, Czibula I, Geritz SAH:

Adaptive Dynamics in a Two-Patch Environment: a Simple Model for

Allopatric and Parapatric Speciation.

IIASA Interim Report IR-97-001.

Journal of Biological Systems (1997) 5, 265-284. 
No. 16 Heino M, Metz JAJ, Kaitala V:

The Enigma of Frequency-Dependent Selection.

IIASA Interim Report IR-97-061.

Trends in Ecology and Evolution (1998) 13, 367-370.

No. 17 Heino M:

Management of Evolving Fish Stocks.

IIASA Interim Report IR-97-062.

Canadian Journal of Fisheries and Aquatic Sciences (1998) 55, 1971-1982.

No. 18 Heino M:

Evolution of Mixed Reproductive Strategies in Simple Life-History Models.

IIASA Interim Report IR-97-063.

No. 19 Geritz SAH, van der Meijden E, Metz JAJ:

Evolutionary Dynamics of Seed Size and Seedling Competitive Ability.

IIASA Interim Report IR-97-071.

Theoretical Population Biology (1999) 55, 324-343.

No. 20 Galis F, Metz JAJ:

Why are there so many Cichlid Species? On the Interplay of Speciation and Adaptive Radiation.

IIASA Interim Report IR-97-072.

Trends in Ecology and Evolution (1998) 13, 1-2.

No. 21 Boerlijst MC, Nowak MA, Sigmund K:

Equal Pay for all Prisoners. / The Logic of Contrition.

IIASA Interim Report IR-97-073.

American Mathematical Society Monthly (1997) 104, 303-307.

Journal of Theoretical Biology (1997) 185, 281-294.

No. 22 Law R, Dieckmann U:

Symbiosis without Mutualism and the Merger of Lineages in Evolution.

IIASA Interim Report IR-97-074.

Proceedings of the Royal Society of London Series B (1998) 265, 1245-1253.

No. 23 Klinkhamer PGL, de Jong TJ, Metz JAJ:

Sex and Size in Cosexual Plants.

IIASA Interim Report IR-97-078.

Trends in Ecology and Evolution (1997) 12, 260-265.

No. 24 Fontana W, Schuster P:

Shaping Space: The Possible and the Attainable in RNA Genotype-Phenotype Mapping.

IIASA Interim Report IR-98-004.

Journal of Theoretical Biology (1998) 194, 491-515. 
No. 25 Kisdi É, Geritz SAH:

Adaptive Dynamics in Allele Space: Evolution of Genetic Polymorphism by Small Mutations in a Heterogeneous Environment.

IIASA Interim Report IR-98-038.

Evolution (1999) 53, 993-1008.

No. 26 Fontana W, Schuster P:

Continuity in Evolution: On the Nature of Transitions.

IIASA Interim Report IR-98-039.

Science (1998) 280, 1451-1455.

No. 27 Nowak MA, Sigmund K:

Evolution of Indirect Reciprocity by Image Scoring. / The Dynamics of

Indirect Reciprocity.

IIASA Interim Report IR-98-040.

Nature (1998) 393, 573-577.

Journal of Theoretical Biology (1998) 194, 561-574.

No. 28 Kisdi É:

Evolutionary Branching Under Asymmetric Competition.

IIASA Interim Report IR-98-045.

Journal of Theoretical Biology (1999) 197, 149-162.

No. 29 Berger U:

Best Response Adaptation for Role Games.

IIASA Interim Report IR-98-086.

No. 30 Van Dooren TJM:

The Evolutionary Ecology of Dominance-Recessivity.

IIASA Interim Report IR-98-096.

Journal of Theoretical Biology (1999) 198, 519-532.

No. 31 Dieckmann U, O'Hara B, Weisser W:

The Evolutionary Ecology of Dispersal.

IIASA Interim Report IR-98-108.

Trends in Ecology and Evolution (1999) 14, 88-90.

No. 32 Sigmund K:

Complex Adaptive Systems and the Evolution of Reciprocation.

IIASA Interim Report IR-98-100.

Ecosystems (1998) 1, 444-448.

No. 33 Posch M, Pichler A, Sigmund K:

The Efficiency of Adapting Aspiration Levels.

IIASA Interim Report IR-98-103.

Proceedings of the Royal Society of London Series B (1999) 266, 1427-1435. 
No. 34 Mathias A, Kisdi É:

Evolutionary Branching and Coexistence of Germination Strategies.

IIASA Interim Report IR-99-014.

No. 35 Dieckmann U, Doebeli M:

On the Origin of Species by Sympatric Speciation.

IIASA Interim Report IR-99-013.

Nature (1999) 400, 354-357.

No. 36 Metz JAJ, Gyllenberg M:

How Should We Define Fitness in Structured Metapopulation Models? Including an Application to the Calculation of Evolutionarily Stable Dispersal Strategies.

IIASA Interim Report IR-99-019.

Research Report A39 (1999), University of Turku, Institute of Applied Mathematics, Turku, Finland.

No. 37 Gyllenberg M, Metz JAJ:

On Fitness in Structured Metapopulations.

IIASA Interim Report IR-99-037.

Research Report A38 (1999), University of Turku, Institute of Applied Mathematics, Turku, Finland.

No. 38 Meszéna G, Metz JAJ:

Species Diversity and Population Regulation: The Importance of Environmental Feedback Dimensionality.

IIASA Interim Report IR-99-045.

No. 39 Kisdi É, Geritz SAH:

Evolutionary Branching and Sympatric Speciation in Diploid Populations.

IIASA Interim Report IR-99-048.

No. 40 Ylikarjula J, Heino M, Dieckmann U:

Ecology and Adaptation of Stunted Growth in Fish.

IIASA Interim Report IR-99-050.

Evolutionary Ecology (1999) 13, 433-453.

No. 41 Nowak MA, Sigmund K:

Games on Grids.

IIASA Interim Report IR-99-038.

In: Dieckmann U, Law R, Metz JAJ (eds.): The Geometry of Ecological Interactions: Simplifying Spatial Complexity, Cambridge University Press, Cambridge, UK, pp. 135150 (2000).

No. 42 Ferrière R, Michod RE:

Wave Patterns in Spatial Games and the Evolution of Cooperation.

IIASA Interim Report IR-99-041.

In: Dieckmann U, Law R, Metz JAJ (eds.): The Geometry of Ecological Interactions: Simplifying Spatial Complexity, Cambridge University Press, Cambridge, UK, pp. 318$332(2000)$. 
No. 43 Kisdi É, Jacobs FJA, Geritz SAH:

Red Queen Evolution by Cycles of Evolutionary Branching and Extinction.

IIASA Interim Report IR-00-030.

No. 44 Meszéna G, Kisdi É, Dieckmann U, Geritz SAH, Metz JAJ:

Evolutionary Optimisation Models and Matrix Games in the Unified Perspective of Adaptive Dynamics.

IIASA Interim Report IR-00-039.

No. 45 Parvinen K, Dieckmann U, Gyllenberg M, Metz JAJ:

Evolution of Dispersal in Metapopulations with Local Density Dependence and Demographic Stochasticity.

IIASA Interim Report IR-00-035.

No. 46 Doebeli M, Dieckmann, U:

Evolutionary Branching and Sympatric Speciation Caused by Different Types of Ecological Interactions.

IIASA Interim Report IR-00-040.

The American Naturalist (2000) 156, S77-S101.

No. 47 Heino M, Hanski I:

Evolution of Migration Rate in a Spatially Realistic Metapopulation Model.

IIASA Interim Report IR-00-044.

No. 48 Gyllenberg M, Parvinen K, Dieckmann U:

Evolutionary Suicide and Evolution of Dispersal in Structured Metapopulations.

IIASA Interim Report IR-00-056.

No. 49 Van Dooren TJM:

The Evolutionary Dynamics of Direct Phenotypic Overdominance: Emergence Possible, Loss Probable.

IIASA Interim Report IR-00-048.

No. 50 Nowak MA, Page KM, Sigmund K:

Fairness Versus Reason in the Ultimatum Game.

IIASA Interim Report IR-00-057.

Science (2000) 289, 1773-1775.

No. 51 De Feo O, Ferrière R:

Bifurcation Analysis of Population Invasion: On-Off Intermittency and Basin Riddling.

IIASA Interim Report IR-00-057.

No. 52 Laaka-Lindberg S, Heino M:

Clonal Dynamics and Evolution of Dormancy in the leafy hepatic Lophozia silvicola.

IIASA Interim Report IR-01-018. 
No. 53 Sigmund K, Hauert C, Nowak MA:

Reward and Punishment in Minigames.

IIASA Interim Report IR-01-031.

No. 54 Hauert C, De Monte S, Sigmund K, Hofbauer J:

Oscillations in Optional Public Good Games.

IIASA Interim Report IR-01-036.

No. 55 Ferrière R, Le Galliard JF:

Invasion Fitness and Adaptive Dynamics in Spatial Population Models.

IIASA Interim Report IR-01-043.

No. 56 de Mazancourt C, Loreau M, Dieckmann U:

Can the Evolution of Plant Defense Lead to Plant-Herbivore Mutualism?

IIASA Interim Report IR-01-053.

The American Naturalist (2001) 158, 109-123.

Issues of the IIASA Studies in Adaptive Dynamics series can be obtained free of charge.

Please contact:

Adaptive Dynamics Network

International Institute for Applied Systems Analysis

Schlossplatz 1

A-2361 Laxenburg

Austria

Telephone +432236 807, Telefax +432236 71313, E-Mail adn@iiasa.ac.at, Internet http://www.iiasa.ac.at/Research/ADN 


\section{Contents}

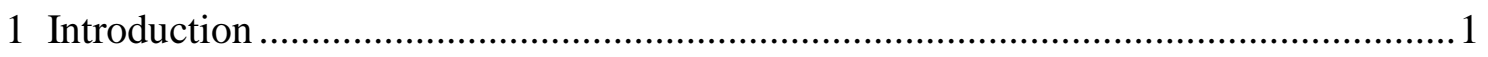

2 Nutrient Cycling in Plant-Herbivore Interactions .....................................................2

Table 1: Variables and parameters of the model ....................................................... 4

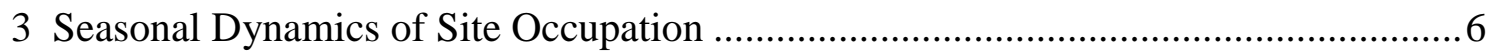

4 Implications of Frequency-dependent Selection and Trade-offs ................................ 7

5 Evolution and Optimization of Plant Performance ................................................. 8

6 Conditions for Plant-Herbivore Mutualism .............................................................. 10

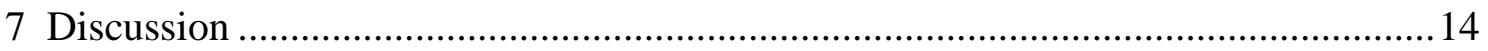

The grazing optimization controversy: can evolution lead to plant-herbivore

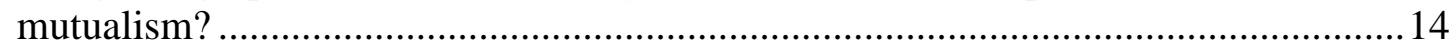

Are mutualistic plant-herbivore interactions likely to occur in nature?..................... 16

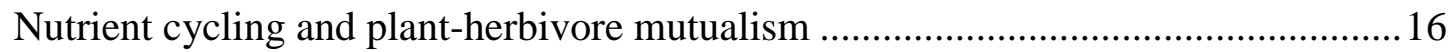

Lotka's maximum power principle: why evolution does not maximize biomass or

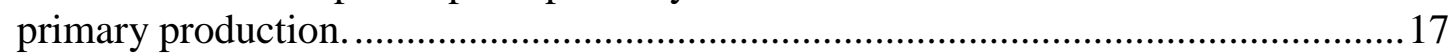

Belsky's argument: antagonistic versus mutualistic coevolution. ............................. 17

Appendix 1 Seed Production as a Linear Combination of Plant Biomass and Primary

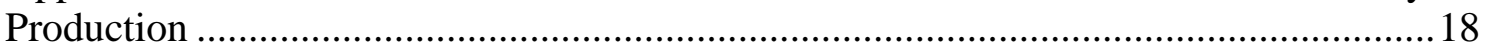

Appendix 2 Locating CSSs and Maximizing Strategies along the Trade-off Curve .....22

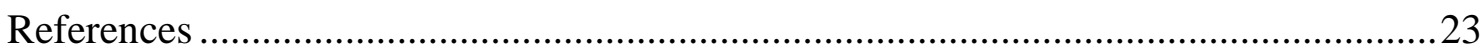




\begin{abstract}
Moderate rates of herbivory can enhance primary production. This hypothesis has led to a controversy as to whether such positive effect can result in mutualistic interactions between plants and herbivores. We present a model for the ecology and evolution of plant-herbivore systems to address this question. In this model, herbivores have a positive indirect effect on plants through recycling of a limiting nutrient. Plants can evolve but are constrained by a trade-off between growth and anti-herbivore defense. Although evolution generally does not lead to optimal plant performance, our evolutionary analysis shows that, under certain conditions, the plant-herbivore interaction can be considered as mutualistic. This requires in particular that herbivores be efficient at recycling nutrient and that plant reproduction be positively correlated with primary production. We emphasize that two different definitions of mutualism need to be distinguished. A first, ecological definition of mutualism is based on the short-term response of plants to herbivore removal, whereas a second, evolutionary definition rests on the long-term response of plants to herbivore removal, allowing plants to adapt to the absence of herbivores. The conditions for an evolutionary mutualism are more stringent than those for an ecological mutualism. A particularly counter-intuitive result is that a higher herbivore recycling efficiency results both in increased plant benefits and in the evolution of increased plant defense. Thus, antagonistic evolution occurs within a mutualistic interaction.
\end{abstract}




\title{
About the Authors
}

\author{
Claire de Mazancourt \\ Department of Biology, Imperial College at Silwood Park \\ Ascot, Berkshire, SL5 7PY, U.K. \\ Michel Loreau \\ Laboratoire d'Écologie, UMR 7625, École Normale Supérieure \\ 46, rue d'Ulm, F-75230 Paris Cedex 05, France \\ Ulf Dieckmann \\ Adaptive Dynamics Network \\ International Institute for Applied Systems Analysis \\ A-2361 Laxenburg, Austria
}

\section{Acknowledgment}

We thank W.F. Morris, P. Nilsson, and an anonymous reviewer for providing valuable comments on a previous version of this paper. 


\section{Can the Evolution of Plant Defense Lead to Plant-Herbivore Mutualism?}

Claire de Mazancourt

Michel Loreau

Ulf Dieckmann

\section{Introduction}

Can moderate rates of herbivory enhance plant primary production? Such a positive effect of herbivory is proposed by the grazing optimization hypothesis (McNaughton 1979, Hilbert et al. 1981, Dyer et al. 1986). This hypothesis suggests that plant primary production can increase with low grazing intensity, reach an optimum at intermediate grazing, before production decreases again when grazing intensity becomes too high. Experimental studies in the Serengeti in Tanzania (McNaughton 1985) and in the La Perouse Bay in Canada (Cargill and Jefferies 1984, Bazely and Jefferies 1989) have demonstrated such increased primary production in plots under herbivory relative to exclosures without herbivores. The relevance of these findings is underlined by theoretical models confirming that, under certain conditions, positive indirect effects of herbivores through nutrient cycling can lead to patterns of grazing optimization (Loreau 1995, de Mazancourt et al. 1998, 1999).

Several authors have even gone further and have suggested that grazing optimization can lead to mutualistic interactions between plants and their herbivores (Owen and Wiegert 1981, Owen and Wiegert 1982, Petelle 1982, Vail 1992), a claim that has attracted much criticism (Silvertown 1982, Belsky et al. 1993, Mathews 1994). According to Belsky et al. (1993), no plausible explanation of a real benefit for the individual plant from herbivory has ever been proposed, and plants "always have an interest in developing a defense strategy." Since plant defenses diminish the amount of nutrient cycling through the herbivore population, they decrease or prevent the positive indirect effects of herbivory. Therefore, even when herbivory could lead to grazing optimization in principle, optimal plant primary production may never be reached under evolving plant defenses.

Several factors, however, are likely to impede the evolution of maximally efficient plant defense strategies. For example, secondary compounds for plant defense must be synthesized, or specific morphological features for defense have to be developed, thus diverting resources from primary functions within the plant. Trade-offs between growth 
and defense are likely to result and have been demonstrated in interspecific as well as intraspecific comparisons (van der Meijden et al. 1988, see Herms and Mattson 1992 for a review). With maximum plant defense then being sub-optimal, grazing optimization becomes conceivable again, even when taking - as demanded by Belsky et al. - the evolution of plant defenses into account.

In this paper we investigate the joint evolution of plant primary production and plant defense. Specifically, we consider the effect of trade-offs between the efficacy of plant defense and the uptake rate of a limiting nutrient - the latter being a critical factor affecting plant growth rate. After introducing an ecological model of plant-herbivore interactions based on nutrient cycling (Sections 2, 3, and 4), we study how evolution within the system is affected by essential characteristics of the nutrient cycle; in particular, we clarify under which ecological conditions plant evolution leads to optimal plant performance (Section 5). To evaluate whether evolved plant-herbivore interactions can be regarded as mutualistic, we distinguish between two different definitions of mutualism, based, alternatively, on short-term or long-term assessments. We directly compare plant performance in the presence and absence of herbivores and show that mutualism between plants and their herbivores is possible under certain conditions (Section 6). These conditions lead to sub-optimal plant performance and to the evolution of better-defended plants, implying that mutualistic interactions can occur together with antagonistic evolution. Finally, we evaluate our findings in comparison with previous research (Section 7).

\section{Nutrient Cycling in Plant-Herbivore Interactions}

In this section we present a simple model for the open cycle of a limiting nutrient in a plant-herbivore system (see Figure 1; an overview of all variables and parameters used in the model is provided in Table 1).

Plants with different strategies $i$ differ in their nutrient uptake rate, $u_{i}$, and in their herbivore consumption rate, $c_{i}$; other ecological features are assumed not to vary with plant strategy. The herbivore consumption rate $c_{i}$ is the annual proportion of standing biomass that is removed by herbivory. We assume that plants influence this rate through their level of defense against herbivores.

In keeping with many recent studies that emphasize ecological consequences of spatial heterogeneity (Huston and DeAngelis 1994, Loreau 1996) we do not assume the mineral nutrient pool in the soil to be spatially homogeneous. Instead, plants have nonoverlapping local nutrient depletion zones, called sites, which are situated around their roots. Each plant absorbs the limiting nutrient from its own local nutrient pool. This spatial heterogeneity prevents direct competitive exclusion (Huston and DeAngelis 1994) which occurs if a single limiting nutrient is provided in a spatially homogeneous nutrient pool (Tilman 1982, 1988). Mineral nutrients can migrate laterally through the soil between nutrient depletion zones through diffusion, transport, or other processes. 


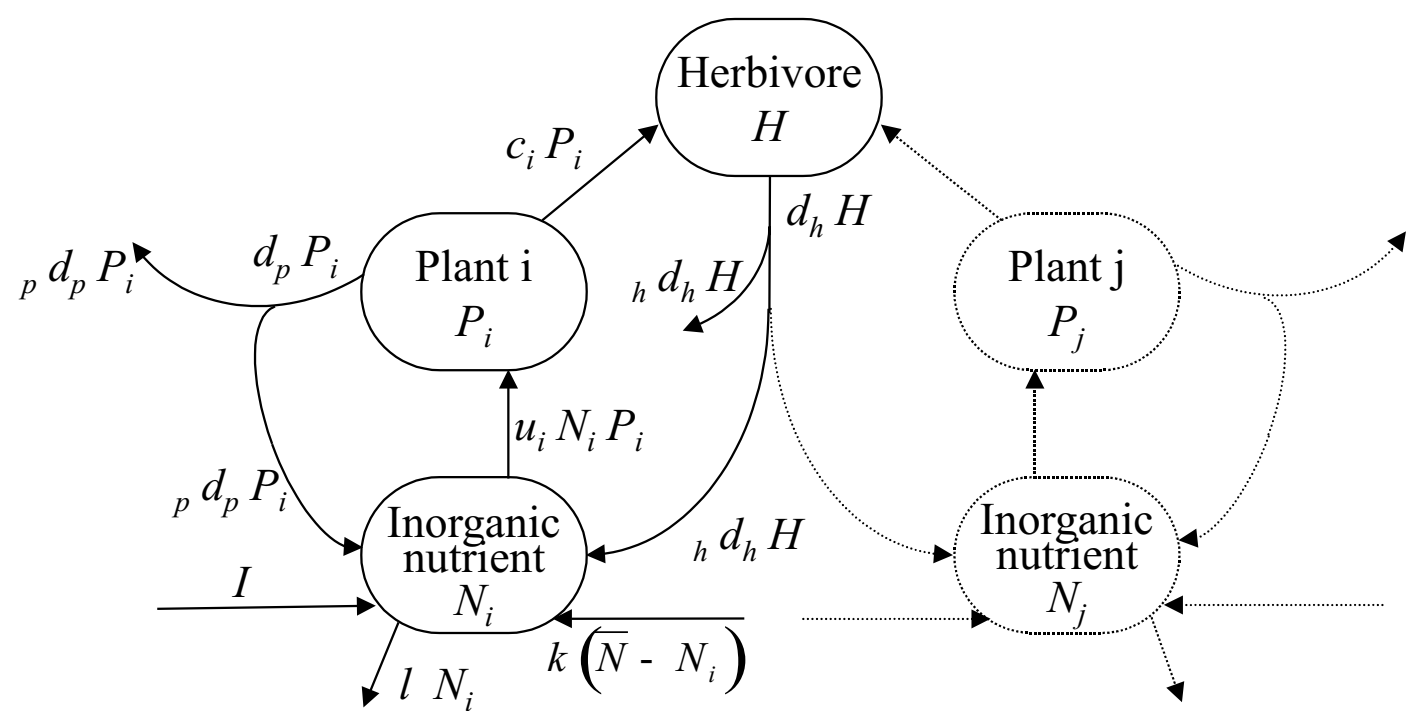

Figure 1: Model for the cycling of a limiting nutrient in an ecosystem comprising plants that are grazed by a generalist herbivore. Plants can employ different strategies; here, two are shown, denoted by $i$ and $j$. Variables and parameters are as defined in Table 1.

Model variables and their rates of change are expressed in units of nutrient concentration per site. Each site is occupied by a single plant with a given strategy, and each strategy $i$ occupies a fraction $S_{i}$ of such sites, so that $\sum_{i} S_{i}=1$.

The following two equations describe the local nutrient dynamics at a site occupied by a plant with strategy $i$,

$$
\begin{aligned}
& \frac{d N_{i}}{d t}=I-l N_{i}+k\left(\bar{N}-N_{i}\right)-u_{i} N_{i} P_{i}+\mu_{p} d_{p} P_{i}+\mu_{h} d_{h} H, \\
& \frac{d P_{i}}{d t}=u_{i} N_{i} P_{i}-d_{p} P_{i}-c_{i} P_{i},
\end{aligned}
$$

where $N_{i}$ is the concentration of mineral nutrient in the soil of a site occupied by a plant with strategy $i$ and $P_{i}$ is the concentration of the limiting nutrient in a plant with strategy $i$. The accumulation of nutrient in the herbivore population per site is described by

$$
\frac{d H}{d t}=\sum_{i} S_{i} c_{i} P_{\mathrm{i}}-d_{h} H
$$

where $H$ is the concentration of the limiting nutrient accumulated in the herbivore population per site. Herbivores are assumed to be distributed uniformly across all sites of the system. The primary production of plants of strategy $i$ is measured by their rate of nutrient uptake,

$$
\Phi_{i}=u_{i} N_{i} P_{i} .
$$

In the following four paragraphs we explain in detail how to interpret the various terms in Equations (1). 
Table 1: Variables and parameters of the model

\begin{tabular}{|c|c|}
\hline Variable & Definition (dimension) \\
\hline$P_{i}$ & Plant $i$ 's nutrient stock in a site (amount of nutrient/site area) \\
\hline$N_{i}$ & $\begin{array}{l}\text { Soil mineral nutrient stock in the local pool of a plant } i \text { in a site } \\
\text { (amount of nutrient/site area) }\end{array}$ \\
\hline$H$ & Herbivore nutrient stock per site area (amount of nutrient/site area) \\
\hline$S_{i}$ & Fraction of sites occupied by plants of strategy $i$ (dimensionless) \\
\hline Parameter & Definition (dimension) \\
\hline$I$ & $\begin{array}{l}\text { Input of inorganic nutrient in the ecosystem per unit of time and area } \\
\text { (amount of nutrient/time /site area) }\end{array}$ \\
\hline$k$ & Migration rate of nutrient in the soil $\left(\right.$ time $\left.^{-1}\right)$ \\
\hline$l$ & Loss rate of mineral nutrient $\left(\right.$ time $\left.^{-1}\right)$ \\
\hline$u_{i}$ & Plant $i$ 's nutrient uptake rate (time ${ }^{-1} /($ amount of nutrient/site area)) \\
\hline$c_{i}$ & Plant $i$ 's consumption rate $\left(\right.$ time $\left.^{-1}\right)$ \\
\hline$d_{p}$ & Plant detritus production rate $\left(\right.$ time $\left.^{-1}\right)$ \\
\hline$\mu_{p}$ & $\begin{array}{l}\text { Fraction of nutrient recycled in the ecosystem along the plant } \\
\text { pathway } \\
\text { (dimensionless) }\end{array}$ \\
\hline$v_{p}$ & $\begin{array}{l}\text { Fraction of nutrient lost for the ecosystem along the plant pathway } \\
\text { (dimensionless) }\end{array}$ \\
\hline$d_{h}$ & Herbivore detritus production rate $\left(\right.$ time $\left.^{-1}\right)$ \\
\hline$\mu_{h}$ & $\begin{array}{l}\text { Fraction of nutrient recycled in the ecosystem along the herbivore } \\
\text { pathway } \\
\text { (dimensionless) }\end{array}$ \\
\hline$v_{h}$ & $\begin{array}{l}\text { Fraction of nutrient lost for the ecosystem along the herbivore } \\
\text { pathway } \\
\text { (dimensionless) }\end{array}$ \\
\hline$\alpha$ & Fraction of plants that die at the end of the season (dimensionless) \\
\hline $\begin{array}{l}\text { Derived } \\
\text { Variables }\end{array}$ & Definition (dimension) \\
\hline $\bar{N}$ & $\begin{array}{l}\text { Mean stock of soil mineral nutrient in a site (amount of nutrient /site } \\
\text { area) }\end{array}$ \\
\hline$\Phi_{i}$ & $\begin{array}{l}\text { Plant } i \text { 's productivity per site area, in terms of the limiting nutrient } \\
\text { (amount of nutrient /time /site area) }\end{array}$ \\
\hline$F_{i}$ & $\begin{array}{l}\text { Seed production of plant } i, \text { at the end of the season } \\
\text { (number of seeds/site area) }\end{array}$ \\
\hline
\end{tabular}


The boundaries of the ecological system are open to nutrient flows: we assume a constant input of nutrient (in inorganic form) into all sites at rate $I$. At each site, mineral nutrient is lost at a rate $l$. Nutrient concentrations in the soil are also altered by nutrient diffusion between sites: inflows of nutrient to a local pool are proportional to (i) the difference between the mean and the local nutrient concentration, $\bar{N}-N_{i}$ (negative values represent outflows), and to (ii) the nutrient diffusion coefficient in the soil, $k$. Assumption (i) is based on a spatially homogeneous mixture of different plant strategies across sites. The mean nutrient concentration is $\bar{N}=\sum_{i} S_{i} N_{i}$.

Plants absorb nutrients at a rate that is proportional to (i) their nutrient uptake rate $u_{i}$, (ii) the local soil concentration $N_{i}$, and (iii) the amount of nutrient $P_{i}$ within the plant, which we assume proportional to plant biomass. Nutrient stored in plants can be recycled through two different pathways, which we call the plant pathway and the herbivore pathway (Figure 1). Nutrient that is not consumed by the herbivore follows the plant pathway. Each plant produces detritus at a rate $d_{p}$. As we are only interested in ecological steady states, time-delayed detritus dynamics have no consequences (de Mazancourt et al. 1998) and are therefore not considered here. A proportion $\mu_{p}$ of nutrient in plant detritus is mineralized and retained in the local nutrient pool around the plant. The rest, i.e. a fraction $v_{p}=1-\mu_{p}$, accumulates as resistant organic matter or is lost and leaves the ecosystem through leaching, volatilization, or other processes. Recycling of plant nutrient in the soil thus occurs at a rate that is proportional to (i) the plants pathway's recycling fraction $\mu_{p}$, (ii) the plant detritus production rate $d_{p}$, and (iii) the amount of nutrient $P_{i}$ within the plant. Plants pathway's recycling fraction is likely to depend on the plant's environment, soil and microbial fauna, but also on characteristics of the plant species (de Mazancourt and Loreau 2000a).

Nutrient consumed by herbivores follows the herbivore pathway. Although more complicated assumptions could readily be made, here we study the simple case of a donor-controlled herbivory: the proportion of standing biomass that is consumed by herbivores then does not depend on the density of herbivores. In previous work we have shown that other forms of herbivory give the same results as donor-controlled herbivory, on an ecological time-scale. The resulting model, however, was much more complicated and difficult to interpret (de Mazancourt et al. 1998). Here we therefore focus on the simple case where herbivore consumption rate is proportional to (i) the amount $P_{i}$ of nutrient within the plant and (ii) the rate $c_{i}$ of plant consumption by herbivores.

Herbivore detritus is not explicitly represented in the model: as for plant detritus, we assume that it is immediately mineralized. While a fraction $\mu_{h}$ of herbivore nutrient is recycled to the soil, the remaining fraction $v_{h}=1-\mu_{h}$ leaves the ecosystem or accumulates as resistant organic matter. Recycled nutrient is uniformly distributed among sites. This is a conservative assumption: if herbivores are sedentary and recycle preferentially on 
the least defended plant type, evolution of less defended plants is favored (de Mazancourt and Loreau 2000b). Note that any detritus that herbivores distribute outside the sites considered in the model amounts to a loss of nutrient from the system and therefore ought to be accounted for in the fraction $v_{h}$ of lost nutrients. Analogously to plant nutrient, recycling of herbivore nutrient to the soil occurs at a rate proportional to (i) the herbivore pathway's recycling fraction $\mu_{h}$, (ii) the rate of herbivore detritus production $d_{h}$, and (iii) the amount $H$ of nutrient within the herbivore population.

Equations (1) specify the nutrient dynamics within a season. As a basis for the subsequent evolutionary analyses, we now consider the ecological dynamics between seasons.

\section{Seasonal Dynamics of Site Occupation}

At the beginning of each growth season, a fraction $\alpha$ of plants die, and the vacant sites are recolonized. Colonization success of different plant strategies depends on their relative contributions to the plant population's seed pool; a plant with strategy $i$ contributes $F_{i}$ seeds to this pool. The fraction of sites occupied by plant strategy $i$ in the next season is then given by

$$
S_{i}(t+1)=(1-\alpha) S_{i}(t)+\alpha \frac{S_{i}(t) F_{i}(t)}{\sum_{j} S_{j}(t) F_{j}(t)} \quad .
$$

Within a season, the number of sites occupied by each strategy does not change. However, the plants grow during the season. At the end of the season, the number of sites occupied by each strategy is updated according to Equation (3).

We assume that the duration of seasons is sufficiently long for nutrient concentrations to attain their equilibria. This might appear as a constraining assumption, but it only requires that the model parameters be carefully chosen to match the seasonal time-scale (de Mazancourt et al. 1998). For example, the state of a compartment such as soil resistant organic matter, with a very long resident time compared to the time-scale of the season, can be considered as constant during one season.

For the plant seed production $F_{i}$ we consider two alternative scenarios: either (i) seeds are produced in proportion to plant biomass, measured by the amount of nutrient in the plant, $F_{i} \propto P_{i}^{*}$, or (ii) seed production is proportional to plant primary production, measured by the rate of nutrient absorption, $F_{i} \propto \Phi_{i}^{*}$, where the asterisk indicates an equilibrium value. These seed production scenarios should be regarded as two extremes along a spectrum of possible dependencies. Both alternatives are underpinned by clear ecological motivations. On the one hand, the amount of nutrient in the plant is positively correlated with plant standing biomass; it is this biomass that can be re-allocated to seed production at the end of each season. Such a scenario is likely for an annual plant $(\alpha=1)$. On the other hand, the amount of nutrient that a plant absorbs per unit time is 
positively correlated with plant primary production and characterizes the amount of resources that plants can continuously divert to seed production during the season. Such a scenario is likely to hold for perennial plants $(\alpha<1)$ and corresponds to classical physiological allocation models, describing the pattern of resource allocation between different functions (Mole 1994). The two scenarios are similar in assuming a constant allocation of plant resources to the production of seeds and vegetative biomass; for the sake of simplicity, we do not explore the consequences of a trade-off between these two functions. Also, both scenarios result in a positive correlation between seed production and plant biomass, which is observed in many empirical studies (Aarssen and Taylor 1992).

We consider the two seed production scenarios introduced here as useful starting points; in Appendix 1 we show that intermediate cases, in which seed production is proportional to a linear combination of plant biomass and primary production, lead to evolutionary outcomes that lie in between the outcomes for the two 'pure' cases. Our two simple cases therefore cover a wider range of options.

\section{Implications of Frequency-dependent Selection and Trade- offs}

For predicting which plant strategy is selected for in our model, we need to account for frequency-dependent selection: the reproductive rate of a plant does not only depend on its own strategy but also on those of all other plants in the system. Specifically, its reproduction depends on herbivore density and nutrient inflow through the soil, both of which are affected by the strategies of all other plants in the system. If, for example, other plants allocate a high fraction of their resources to defense, a plant with weak defense is expected to experience a particularly high selection pressure toward stronger defense.

The theory of adaptive dynamics (Metz et al. 1996, Dieckmann and Law 1996, Dieckmann 1997, Geritz et al 1998) takes into account frequency dependence. An exhaustive study of evolutionary outcomes in the model introduced above is not the focus of the present paper; such a systematic analysis is presented elsewhere (de Mazancourt 1998, C. de Mazancourt, M. Loreau, and U. Dieckmann, unpublished manuscript).

Natural populations of plants can neither increase their nutrient uptake rate indefinitely, nor completely avoid consumption by herbivores. We therefore assume that plant evolution is confined between two extreme strategies: at one extreme, plants maximize the efficiency of their anti-herbivore defense system, resulting in a strategy $D$ with a minimum rate of herbivory and a minimum nutrient uptake rate, $D=\left(c_{\min }, u_{\min }\right)$; at the other extreme, they maximize the efficiency of their nutrient uptake system, resulting in a strategy $U$ with a maximum nutrient uptake rate and a maximum herbivore consumption rate, $U=\left(c_{\max }, u_{\max }\right)$. Intermediate plant strategies $(c, u)$ are confined on a 
trade-off curve. This trade-off reduces the originally two-dimensional strategy space $(c, u)$ of plants to a single dimension so that we can characterize each plant strategy by its herbivore consumption rate $c$ (see Appendix 2).

In the following sections, we focus attention on trade-offs that result in continuously stable strategies, or CSSs (Eshel and Motro 1981, Eshel 1983). A CSS has two independent properties. First, it is convergence stable in the sense of Christiansen (1991): for a given resident strategy, only mutants closer to the convergent stable strategy can invade, i.e., the evolutionary dynamics converges towards this strategy. Second, it is evolutionarily stable in the sense of Maynard Smith (Maynard Smith and Price 1973, Maynard Smith 1982): when the strategy is resident, it cannot be invaded by any other mutant strategy. An evolutionarily stable strategy, once attained, is an endpoint of the evolutionary process, and the property of convergence stability ensures that this evolutionary endpoint can be reached. It can be shown that, for the model considered here, evolutionarily and convergence stable outcomes are expected for realistic parameter values (de Mazancourt 1998, C. de Mazancourt, M. Loreau, and U. Dieckmann, unpublished manuscript).

\section{Evolution and Optimization of Plant Performance}

In this section we explore the implications of evolution for plant performance. We investigate how essential characteristics of the nutrient cycle affect the strategy favored by evolution, and whether this strategy coincides with the one that maximizes primary production or plant biomass. In other words, can optimal plant biomass or primary production be reached under evolving plant defenses? To assess this question, which lies at the heart of the grazing optimization controversy, we compare the CSSs for each seed production scenario (proportional to plant biomass or to primary production) with the two strategies that maximize plant biomass or primary production.

Figure 2 shows the relative positions of the four strategies; the method used for obtaining these results is outlined in Appendix 2. The various cases depicted in Figure 2 illustrate the influence of different model parameters. In particular, the effects of the fraction of nutrient recycled along the plant pathway, of the fraction of nutrient recycled along the herbivore pathway, and of the migration rate of nutrient in the soil are demonstrated.

Let us first focus on how the two maximizing strategies are affected by varying model parameters. Consumption has a greater impact on plant biomass than it has on primary production because consumption affects soil nutrient concentration $N$ such that, at equilibrium, $\Phi_{i}^{*}=u_{i} N_{i}^{*} P_{i}^{*}=\left(d_{p}+c_{i}\right) P_{i}^{*}$. Consequently, maximizing biomass always requires a smaller consumption rate than does maximizing primary production (Figures $2 \mathrm{~A}$ to $2 \mathrm{D}$ ). Recycling of plant detritus shifts the maximizing strategies toward betterdefended plants (compare Figures 2A and 2B). This is because a smaller consumption increases the nutrient conservation in the system, as plant nutrient flows through the 
A

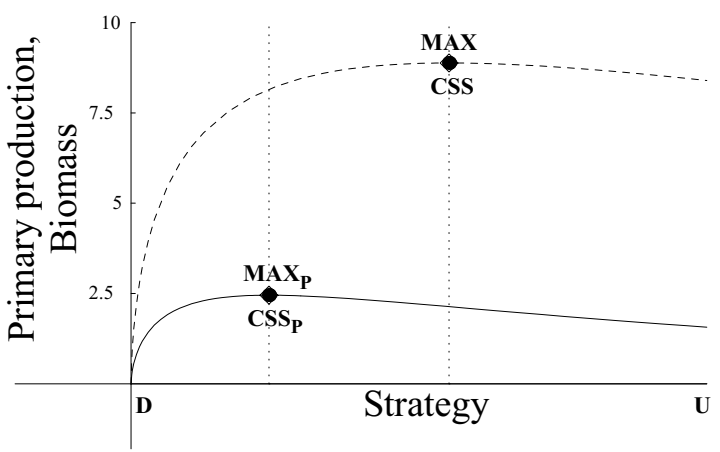

C

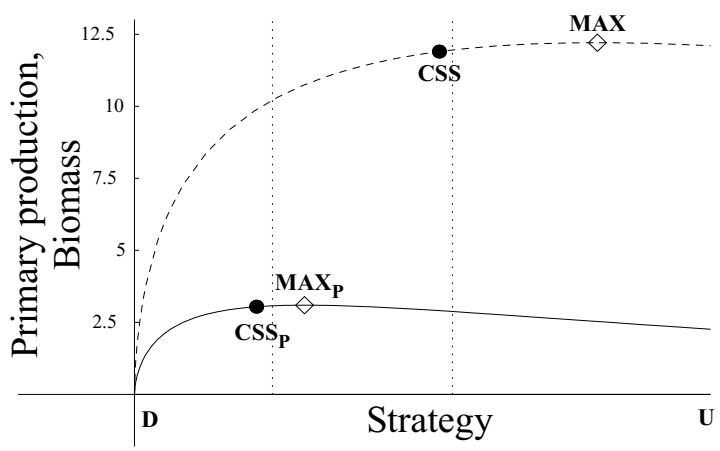

B

Plant recycling

No nutrient migration in the soil

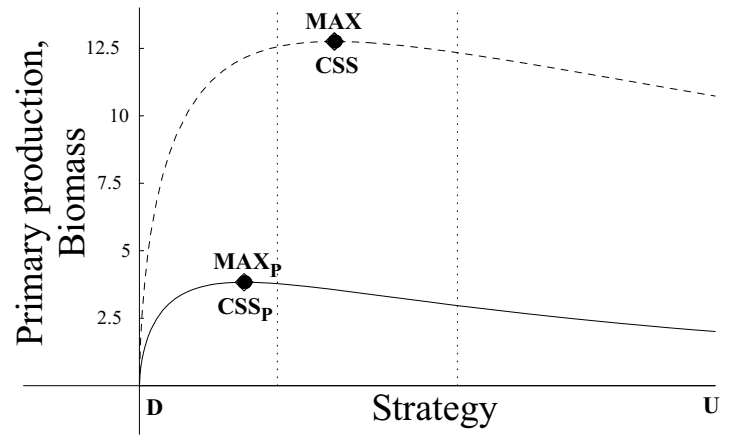

D

No recycling

Maximal nutrient migration in the soil

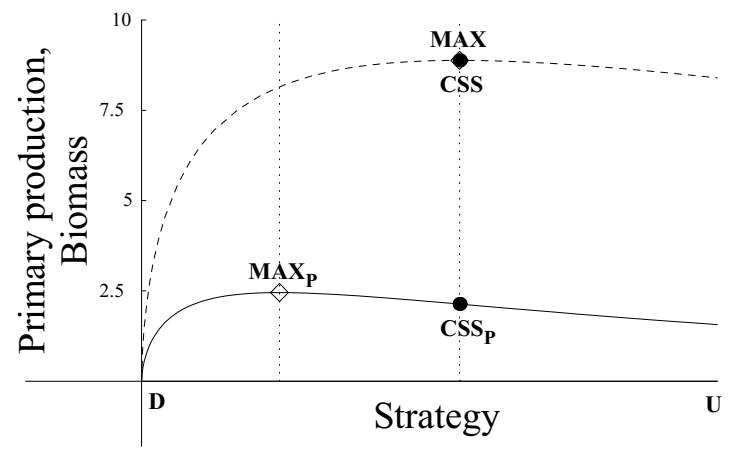

Figure 2: Biomass (solid line) and primary production (dashed line) as a function of plant strategies ranging from the maximally defended plant strategy $D$ to the minimally defended strategy $U$ that allocates most resources to nutrient uptake. Evolutionary outcomes (continuously stable strategies) are $\operatorname{CSS}_{P}$ (seed production proportional to plant biomass) and $\operatorname{CSS}_{\Phi}$ (seed production proportional to primary production). $M A X_{P}$ is the strategy that maximizes plant biomass and $M A X_{\Phi}$ maximizes primary production. (A) No migration of nutrient in the soil and no plant or herbivore nutrient recycling. For comparison, strategies $M A X_{P}$ and $M A X_{\Phi}$ resulting for this baseline case are indicated by dotted lines and repeated unaltered in the three other panels. (B) Effect of plant nutrient recycling. (C) Effect of herbivore nutrient recycling. (D) Effect of migration of nutrient in the soil (shown for an infinite migration rate $k$ of nutrient in the soil). Parameters: $I=28.11 \mathrm{~kg} \cdot \mathrm{N} \cdot \mathrm{ha}^{-1} \cdot \mathrm{yr}^{-1} ; l=1.80 \mathrm{yr}^{-1} ; d_{p}=2.15 \mathrm{yr}^{-1}$; trade-off function: $c_{\min }=0.54 \mathrm{yr}^{-1}$; $c_{\text {max }}=3.20 \mathrm{yr}^{-1} ; u_{i}=0.17+0.17\left(c_{i}-c_{\text {min }}\right)^{0.63}$ ha.kg. $\mathrm{N}^{-1} \cdot \mathrm{yr}^{-1}$. (A) $\mathrm{v}_{p}=\mathrm{v}_{h}=1 ; k=0 \mathrm{yr}^{-1}$. (B) $\mathrm{v}_{p}=0.46 ; \mathrm{v}_{h}=1 ; k=0 \mathrm{yr}^{-1}$. (C) $\mathrm{v}_{p}=0.95 ; \mathrm{v}_{h}=0.72 ; k=0 \mathrm{yr}^{-1}$. (D) $\mathrm{v}_{p}=\mathrm{v}_{h}=1 ; k=1,000,000 \mathrm{yr}^{-1}$.

plant pathway. Recycling of herbivore detritus shifts the maximizing strategies toward less defended plants (compare Figures $2 \mathrm{~A}$ and 2C): because herbivore detritus is recycled whereas plant detritus is not, here it is the greater consumption of plants by herbivores that improves conservation of nutrient in the system. Migration of nutrient in the soil does not change the positions of the two maximizing strategies, since it does not influence biomass and production in a monoculture, in which the mean and the local nutrient concentrations in the soil are equal. 
We can now compare the results of the previous paragraph with the effect model parameters have on the position of the CSSs. When plant recycling occurs but both herbivore recycling and migration of mineral nutrient are absent, evolution simply leads toward those strategies that maximize biomass or primary production, depending on the scenario used for seed production (compare Figures 2A and 2B). However, two factors - herbivore recycling and migration of mineral nutrient - can cause the CSSs to depart from the corresponding maximizing strategies by giving more importance either to defense or to nutrient uptake. Herbivore recycling alone favors plants that are better defended: better-defended plants benefit from nutrient recycled through herbivory on neighboring plants, while also incurring a lower cost from herbivory and thus can invade less defended plants (compare Figures 2A and 2C). For CSSs resulting from the primary production scenario this effect is proportional to plant recycling. Migration of mineral nutrient in the soil selects for plants with the best capability of local nutrient depletion: they benefit from the nutrient flow from neighboring rooting zones. This leads to selection for plants with higher nutrient uptake rates (compare Figure 2D with $2 \mathrm{~A}$ to $2 \mathrm{C}$ ). Evolution then leads toward the same strategy that maximizes primary production when no recycling occurs (compare Figure $2 \mathrm{D}$ with $2 \mathrm{~A}$ ) because this strategy minimizes losses of soil inorganic nutrient. Intermediate cases lie between the extreme situations discussed above.

It is interesting to note that all the patterns described in Figure 2 are general and, in the presence of a CSS, apply irrespective of any specific assumptions regarding the trade-off curve.

\section{Conditions for Plant-Herbivore Mutualism}

So far we have shown that plant evolution does not always maximize primary production or biomass. Remarkably, the same parameter that can enhance primary production in the presence of herbivores, the fraction of nutrient along the herbivore pathway, leads to sub-optimal plant performance through the evolution of plant defense. Despite being sub-optimal, however, evolution could still lead to mutualistic interactions, as suggested by several authors (Owen and Wiegert 1981, Owen and Wiegert 1982, Petelle 1982, Vail 1992).

The classical method for identifying mutualistic ecological interactions is based on removal experiments or press perturbations (Schoener 1983, Bender et al. 1984, Krebs 1985): if each of the two populations decreases in performance (i.e., in density, biomass, or production) after the other population with which it interacts has been removed or is kept at low densities, the interaction is considered to be mutualistic.

In spite of the heuristic value of such a definition, its practical application requires careful consideration of several details. First, responses to different measures of performance may not always point toward the same conclusion. Second, results can be qualitatively affected by the strength of perturbations. Third, the short- and long-term 
effects of a removal should be distinguished: while the former reflects the ecological response of a system, the latter also accounts for any potential evolutionary change resulting from a perturbation (Douglas and Smith 1989, Law and Dieckmann 1998). This leads to two different definitions of mutualism: we refer to these as ecological and evolutionary mutualisms, respectively (C. de Mazancourt, M. Loreau, and U. Dieckmann, unpublished manuscript). For an ecological mutualism, the performance of partners is evaluated before any evolution can occur, whereas for an evolutionary mutualism, the mutual benefit has to remain (or arise) after adaptation to the removal has taken place. The beneficial effect of plants on herbivores is straightforward and needs no further consideration. We investigate the potentially beneficial effect of herbivores on plants by model-based herbivore removal experiments that allow us to compare plant performances with and without herbivores over short and long time spans (Figure 3).

In the presence of herbivores, equilibrium biomass and primary production of a monomorphic population with strategy $\left(c_{C S S}, u_{C S S}\right)$ are given by, respectively:

$$
\begin{aligned}
& P_{C S S}^{*}=\frac{I-l\left(d_{p}+c_{C S S}\right) / u_{C S S}}{v_{p} d_{p}+v_{h} c_{C S S}}, \\
& \Phi_{C S S}^{*}=\left(d_{p}+c_{C S S}\right) P_{C S S}^{*} .
\end{aligned}
$$

Starting from the evolutionarily stable situation $\left(c_{C S S}, u_{C S S}\right)$, we can determine the short-term response of the plant population to the removal of herbivores: biomass and primary production in the post-removal ecological equilibrium are given by

$$
\begin{aligned}
& P_{\mathrm{eco}}^{*}=\frac{I-l d_{p} / u_{C S S}}{v_{p} d_{p}}, \\
& \Phi_{\mathrm{eco}}^{*}=d_{p} P_{\mathrm{eco}}^{*} .
\end{aligned}
$$

By comparing Equations (4) and (5) we see that in the short-term response to herbivore removal (i) plant biomass is always increased and (ii) primary production is decreased if nutrient loss along the herbivore pathway is sufficiently smaller than along the plant pathway,

$$
v_{h} / v_{p}<1-\frac{\left(d_{p}+c_{C S S}\right) / u_{C S S}}{I / l-d_{p} / u_{C S S}} .
$$

A necessary (but not sufficient) condition for Inequality (6a) to be fulfilled is that its right-hand side be positive: the nutrient input into the system has to exceed a threshold value,

$$
I / l>\frac{2 d_{p}+c_{C S S}}{u_{C S S}} .
$$

We can thus conclude that herbivore removal always has a positive short-term effect on plant biomass. It also has a positive short-term effect on primary production, unless Inequality (6a) is fulfilled, i.e., unless nutrient recycling is sufficiently more efficient 
along the herbivore pathway than along the plant pathway. Inequalities (6a) and (6b) are thus the prerequisites for grazing optimization to occur.

We now extend the preceding analysis to encompass the plants' evolutionary response to herbivore removal. Without herbivores, plants should not allocate any resources to defense, and therefore evolve toward the strategy with maximal uptake rate $u_{\max }$. The biomass and primary production after herbivore removal and plant evolution are thus

$$
\begin{aligned}
& P_{\mathrm{evo}}^{*}=\frac{I-l d_{p} / u_{\mathrm{max}}}{v_{p} d_{p}}, \\
& \Phi_{\mathrm{evo}}^{*}=d_{p} P_{\mathrm{evo}}^{*} .
\end{aligned}
$$

By comparing Equations (5) and (7) we see that evolution after herbivore removal always leads to increased plant biomass and primary production, $P_{\mathrm{evo}}^{*}>P_{\mathrm{eco}}^{*}$ and $\Phi_{\mathrm{evo}}^{*}>\Phi_{\mathrm{eco}}^{*}$. Comparing Equations (4) and (7) shows that the long-term response to herbivore removal always increases plant biomass relative to the evolutionary equilibrium attained in the presence of herbivores, $P_{\mathrm{evo}}^{*}>P_{C S S}^{*}$. Also, primary production after herbivore removal and plant evolution is lower than at the pre-removal CSS, $\Phi_{\text {evo }}^{*}<\Phi_{C S S}^{*}$, if

$$
v_{h} / v_{p}<1-\left(\frac{d_{p}+c_{C S S}}{c_{C S S}}\right)\left(\frac{\left(d_{p}+c_{C S S}\right) / u_{C S S}-d_{p} / u_{\max }}{I / l-d_{p} / u_{\max }}\right) \text {. }
$$

Again, this condition can only be fulfilled if its right-hand side is positive, i.e.,

$$
I / l>\frac{2 d_{p}+c_{C S S}+\left(1-u_{C S S} / u_{\max }\right) d_{p}^{2} / c_{C S S}}{u_{C S S}} .
$$

After herbivore removal, primary production either increases (if $u_{C S S}<u_{\max }$ ) or remains constant (if $u_{C S S}=u_{\max }$ ). This implies $\Phi_{\text {evo }}^{*} \geq \Phi_{\text {eco }}^{*}$ and Inequalities (8) are therefore more restrictive than Inequalities (6).

We thus conclude that herbivore removal has a positive effect on plant biomass in the short term, and even more so in the long term. Removal also has a positive effect on primary production if herbivores are not sufficiently efficient at recycling nutrient, see Inequalities (6a) and (8a). If, however, nutrient loss via the herbivore pathway is sufficiently smaller than via the plant pathway, herbivore removal results in a loss of plant performance in terms of primary production. In other words, if herbivores contribute enough to nutrient conservation, both the short-term and long-term responses to herbivore removal can indicate a plant-herbivore mutualism. The conditions for an ecological mutualism turn out to be less stringent than those for an evolutionary mutualism. Yet, in the range of parameters explored, these two conditions appear to be only marginally different. Figure 3 shows primary production and plant-herbivore 

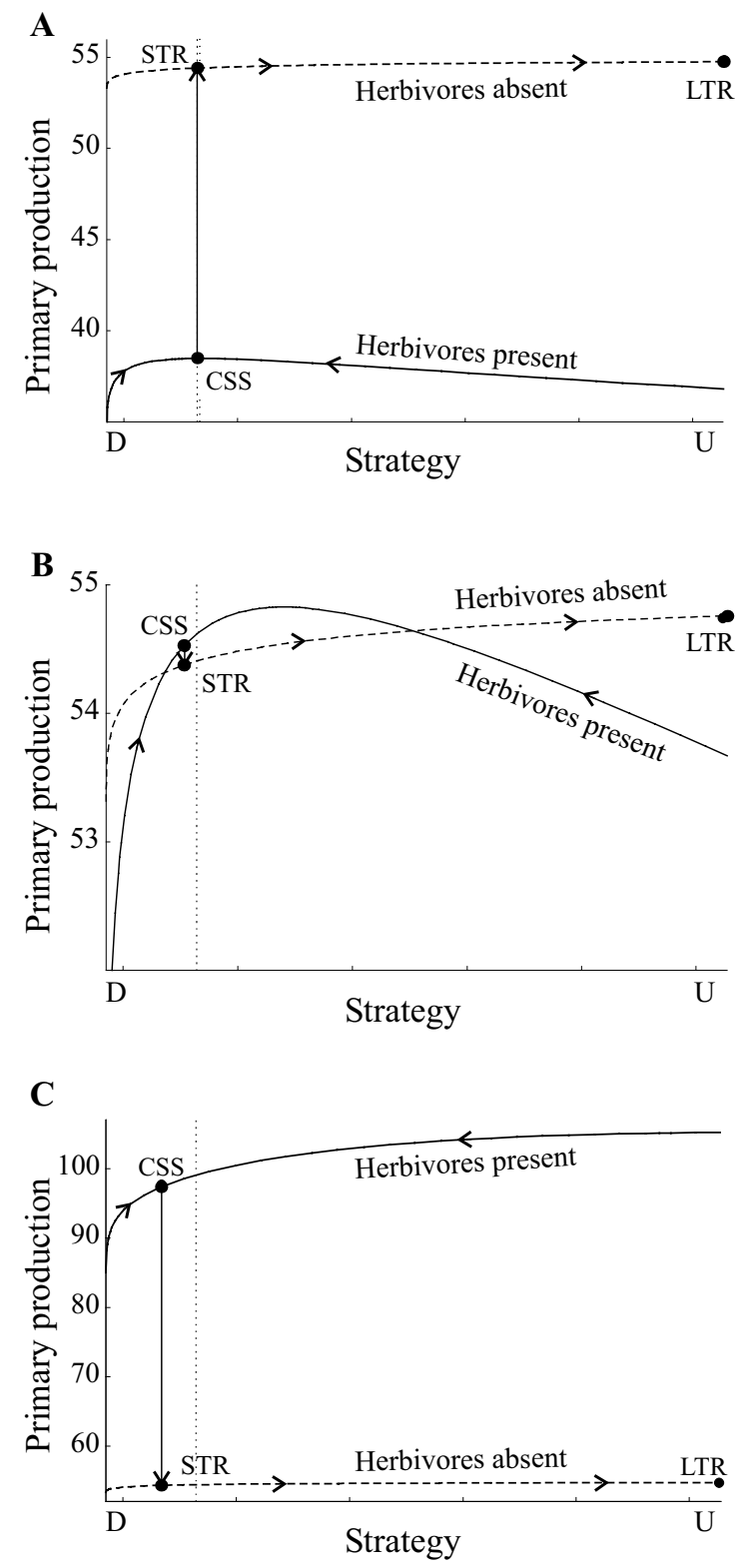

Figure 3: Primary production along the trade-off curve of plant strategies in the presence of herbivores (solid line) and in their absence (dashed line). When herbivores are present, evolution leads to a continuously stable strategy (CSS). To test whether plant-herbivore interactions are mutualistic we compare plant performance in the presence and in the absence of herbivores. Two different plant responses need to be distinguished: in the short-term response (STR), herbivores have been removed but plants have not yet adapted to the herbivore-free situation; in the long-term response (LTR), herbivores have been removed and plants have had time to adapt. (A) No mutualism: plant performance is always decreased in the presence of herbivores. (B) Ecological mutualism: plant performance is decreased by the short-term response to herbivore removal (STR is lower than CSS). However, on the long term, the removal leads to an increase in primary production (LTR is higher than CSS), and there is no evolutionary mutualism. (C) Ecological and evolutionary mutualism: herbivore removal results, on the short term and on the long term, in decreased plant performance (CSS higher than STR and LTR). In all three panels, the dotted line shows the CSS for case (A) to facilitate comparison between panels. Parameters: $I=39.77$ kg.N.ha ${ }^{-1} . \mathrm{yr}^{-1} ; l=4.57 \mathrm{yr}^{-1} ; k=0.47 \mathrm{yr}^{-1} ; d_{p}=0.57 \mathrm{yr}^{-1} ; v_{p}=0.72$; trade-off function: $c_{\min }=2.85 \mathrm{yr}^{-1} ; c_{\max }=8.27 \mathrm{yr}^{-1} ; u_{i}=1.88+2.75\left(c_{i}-c_{\min }\right)^{0.43}$ ha. $\mathrm{kg} \mathrm{N}^{-1} \cdot \mathrm{yr}^{-1}$. (A) $v_{h}=0.95$. (B) $\mathrm{v}_{h}=0.636$. (C) $\mathrm{v}_{h}=0.30$. 
recycling efficiency is too low and the interaction is exploitative. In Figure 3B, the interaction is an ecological mutualism but not an evolutionary mutualism. In Figure 3C, herbivore recycling efficiency is sufficiently high for the interaction to be both an ecological and an evolutionary mutualism.

Conditions for mutualism depend on the model parameter in a more complex way than Inequalities (6) and (8) might suggest: both uptake and consumption at the CSS depend on the model parameters.

It is instructive to understand the shape of the curves shown in Figure 3. In the absence of herbivores, both biomass and primary production increase along the trade-off curve: as plant nutrient uptake increases, nutrient loss through leaching decreases. In the presence of herbivores, two factors must be taken into account. First, the effect of herbivory: biomass always decreases with the consumption rate, as soon as herbivores induce some nutrient loss from the system $\left(v_{h}>0\right)$; primary production increases if the herbivore recycling efficiency is larger than the fraction of nutrient recycled along the plant pathway. The second effect results from leaching: depending on the shape of the trade-off, leaching can either increase or decrease along the trade-off curve; this results, respectively, in decreased or increased biomass and primary production. In the example featured in Figure 3, leaching presents a humped shape along the trade-off, which results in a humped shape for primary production.

While the analysis in this section is based on a donor-controlled herbivory, preliminary results for recipient-controlled Lotka-Volterra interactions point to identical conclusions.

\section{Discussion}

We now evaluate our findings in the light of various hypotheses and ongoing controversies concerning the evolutionary ecology of plant-herbivore interactions.

\section{The grazing optimization controversy: can evolution lead to plant- herbivore mutualism?}

In Section 6 we have seen how to distinguish between the short-term and long-term consequences of removal experiments. Both alternative perspectives lead to useful definitions of mutualism: interactions are mutualistic in the ecological sense if removal results in a short-term loss of performance; they are mutualistic in the evolutionary sense when this loss occurs in the long-term (Figure 3). In the latter case we can think of a population adapting after the removal of its mutualistic partner, but the evolutionary perspective is equally relevant when considering a situation before the two partners first came into close ecological contact.

While the two definitions of mutualism may lead to the same conclusion, results of these independent assessments may also challenge each other. Of particular interest to our present discussion is the case when interactions are mutualistic in the ecological but 
not in the evolutionary sense. To characterize this combination, Douglas and Smith (1989) have introduced the notion of evolved dependence, which they contrast with that of evolutionary benefit. The former may merely reflect the evolutionary consequences of a past history of tight ecological interaction, and may vanish once the association is lost. For example, during association and evolution with a herbivore, and due to some side effects of herbivory, a plant may have lost its ability to perform well in the absence of that herbivore, making it dependent on its exploiter (Figure 3B).

Some plants have been shown to overcompensate for herbivory (i.e., they produce more seeds when grazed). For these plants, herbivory releases apical dominance and grazed plants therefore produce more tillers and more seeds than ungrazed plants (Paige and Whitham 1987, Paige 1999, Lennartsson et al 1997, 1998, Strauss and Agrawal 1999, C. de Mazancourt, M. Loreau, and U. Dieckmann, unpublished manuscript). One explanation of this effect may be that, in the course of its evolutionary history with the herbivore, the plant has evolved a mechanism by which reserves are stored and mobilized when the risk of herbivory is over (Nilsson et al. 1996a, 1996b). This mechanism is advantageous in the presence of the herbivore, but not in its abscence: the plant has evolved a dependence on the herbivore. An evolutionary benefit, on the other hand, only occurs when interactions are mutualistic both in the ecological and in the evolutionary sense (Figure 3C).

We have seen in the previous section that when plant seed production is proportional to plant biomass, herbivore removal has a positive short-term and long-term effect on plant biomass and hence on plant seed production. The effect of herbivores on plants is then always exploitative. However, when plant fecundity is proportional to primary production, and if the nutrient input to the system is sufficient so that Inequalities (6a) and (8a) can be fulfilled, increasing the efficiency of nutrient recycling by herbivores leads to mutualistic plant-herbivore interactions (Figure 3). At low levels of herbivore recycling efficiency, the interaction is exploitative (Figure $3 \mathrm{~A}$ ). But when herbivore recycling efficiency is increased to intermediate levels, the plant-herbivore interaction becomes mutualistic from an ecological point of view (Figure 3B). Yet, plants do not benefit from herbivores but may rather have evolved a dependence on them. Eventually, when herbivores recycle nutrient with a high efficiency, the plant-herbivore interaction becomes mutualistic in the evolutionary sense and plants truly benefit from herbivores (Figure 3C).

Distinguishing between ecological and evolutionary mutualisms, with the associated concepts of evolved dependence and evolutionary benefit, is of particular relevance in the context of the grazing optimization controversy (C. de Mazancourt, M. Loreau, and U. Dieckmann, unpublished manuscript). Although some authors (Douglas and Smith 1989, Belsky et al. 1993, Tuomi et al. 1994, Järemo et al. 1999) appear to be willing to adopt an evolutionary definition of mutualism, it is evident from the results presented 
here that this perspective is more restrictive than the corresponding ecological definition.

\section{Are mutualistic plant-herbivore interactions likely to occur in nature?}

We have shown in this paper that plant-herbivore mutualism can occur if (1) the fraction of nutrients recycled through the herbivore pathway is sufficiently higher than the fraction of nutrients recycled through the plant pathway and (2) plant reproduction is proportional to primary production, or at least sufficiently dependent on it (Appendix 1). De Mazancourt et al. (1999) discussed the likelihood of Condition (1) to be met. That study shows that herbivory is likely to lead to improved conservation of nutrients in some ecosystems. The specific example we considered is a savanna ecosystem, where fires volatilize nearly all the nitrogen remaining in plant standing biomass at the end of each season. Herbivores can promote nutrient conservation in such a system by reducing plant standing biomass.

The current literature does not yet allow evaluating the likelihood of Condition (2) to be met. A primary reason for this state of affairs lies in the fundamental difficulties associated with measuring primary production, especially in the presence of herbivores. Therefore, most experiments measure plant reproduction as a function of plant standing biomass, and do not permit discrimination between the two hypothetical scenarios of seed production considered here. Yet, it seems very likely that plant reproduction depends on both standing biomass and uptake fluxes. As shown in Appendix 1, intermediate scenarios of seed production can also result in mutualistic interaction, although conditions then are more stringent.

\section{Nutrient cycling and plant-herbivore mutualism}

The present model shows that, if plant defense is costly, plants might be "forced" into a mutualistic interaction with their herbivores: although one component of the selection pressure favors ever-improving defenses, this process is stopped by the cost of such defense strategies.

In a different model (de Mazancourt and Loreau 2000b), we showed another process that might lead to the evolution of plant-herbivore mutualism: spatial heterogeneity of the interaction. If recycling occurs primarily beneath plants preferred by the herbivore, as would occur for small sedentary herbivores like caterpillars, it is primarily those plants that benefit from nutrient recycling along the herbivore pathway. Under such conditions, mutualism can occur more easily.

In the present model, taking into account the spatial heterogeneity of the interaction would drive evolutionary outcomes closer to the strategy that maximizes primary production or biomass and would thus make the conditions for mutualism less stringent. 


\section{Lotka's maximum power principle: why evolution does not maximize biomass or primary production.}

We have shown that evolution does not always lead to the maximization of primary production or biomass. This is in contradiction to Lotka's (1922) maximum power principle, according to which "evolution proceeds in such direction as to make the total energy flux through the system a maximum compatible with the constraints." Similar principles were also formulated by other authors (Odum and Pinkerton 1955, Brown et al. 1993).

Two factors lead away from these maxima: herbivore recycling and migration of nutrient in the soil (section 5). The maximum power principle does not hold because it does not account for the outcome of competitive interactions between plant types: the performance of a plant depends not only on its own strategy, but also on those of its competitors.

\section{Belsky's argument: antagonistic versus mutualistic coevolution.}

In her 1986 paper, Belsky asked whether grasses and their grazers have coevolved mutualistically. Observing the numerous anti-herbivore defenses that grasses have evolved, she then concluded that "indisputably [...], these adaptations suggest antagonistic relationship, not a mutualistic one."

In the model presented in this paper, mutualistic interactions between plants and their herbivores may arise when herbivores are sufficiently more efficient at recycling nutrient than are plants. As described above, increasing nutrient recycling by herbivores can result in more and more mutualistic plant-herbivore interactions (Figure 3). Notice, however, that along the same gradient of recycling efficiency there is selection toward increased levels of plant defense, at the expense of reduced nutrient uptake (Figure 2A and $2 \mathrm{C}$ ). This results from the fact that defended strategies benefit from herbivore recycling and yet suffer less consumption by herbivores; such strategies are therefore selected when herbivore recycling increases. Surprisingly, the increase of plant defense against herbivores may go hand in hand with the build-up of mutualistic plant-herbivore interactions. Although this finding may seem paradoxical at first sight, such evolutionary conflicts between partners are well known to exist in mutualistic interactions (Anstett et al. 1997, Law and Dieckmann 1998): mutualism can arise even though one partner evolves enhanced defenses. In other words, antagonistic evolution can occur within a mutualistic interaction.

The investigations of plant responses to herbivory presented in this paper are rooted in a description of nutrient cycling and link the physiological, ecological, and evolutionary aspects of plant-herbivore interactions. Tying together these different aspects of ecological research into an integrated perspective allows us to consider the evolutionary consequences of ecological interactions and the ecological implications of evolutionary change. 


\section{Appendix 1 Seed Production as a Linear Combination of Plant Biomass and Primary Production}

In this appendix we show that, if seed production is a linear combination of plant biomass and primary production, the evolutionary outcome is intermediate between these two extreme cases. In general, the evolutionary outcome is determined by the shape of the trade-off curve relative to the invasion boundaries of strategies that lie on that curve (Appendix 2). For the purpose of the present appendix, we have to demonstrate that, for the linear combination, the slope $S V$ of the local invasion boundary is intermediate between the slopes $S V_{P}$ and $S V_{\phi}$ that result from the two extreme scenarios.

Assume that seed production is a linear combination of plant biomass and primary production,

$$
F_{i}=\beta P_{i}^{*}+(1-\beta) \Phi_{i}^{*}
$$

Then, the slope of the local invasion boundary is:

$$
S V=\left[-\frac{\partial F_{m}}{\partial c_{m}} / \frac{\partial F_{m}}{\partial u_{m}}\right]_{\substack{c_{m}=c_{r} \\ u_{m}=u_{r}}}=\left[\frac{\beta\left(-\frac{\partial P_{m}^{*}}{\partial c_{m}}\right)+(1-\beta)\left(-\frac{\partial \Phi_{m}^{*}}{\partial c_{m}}\right)}{\beta \frac{\partial P_{m}^{*}}{\partial u_{m}}+(1-\beta) \frac{\partial \Phi_{m}^{*}}{\partial u_{m}}}\right]_{\substack{c_{m}=c_{r} \\ u_{m}=u_{r}}}
$$

In comparison, the slopes of the local invasion boundaries for the extreme cases where seed production is proportional to plant biomass and to primary production are

$$
S V_{P}=\left[-\frac{\partial P_{m}^{*}}{\partial c_{m}} / \frac{\partial P_{m}^{*}}{\partial u_{m}}\right]_{\substack{c_{m}=c_{r} \\ u_{m}=u_{r}}}
$$

and

$$
S V_{\Phi}=\left[-\frac{\partial \Phi_{m}^{*}}{\partial c_{m}} / \frac{\partial \Phi_{m}^{*}}{\partial u_{m}}\right]_{\substack{c_{m}=c_{r} \\ u_{m}=u_{r}}}
$$

respectively. The biomass and primary production of a mutant decrease when the consumption rate increases and increase when the uptake rate increases. Therefore, the derivatives with respect to the consumption rate, $c_{m}$, are negative while the derivatives with respect to the uptake rate, $u_{m}$, are positive. As a consequence, it can be shown that both $S V_{P}-S V$ and $S V-S V_{\Phi}$ have the same sign as $S V_{P}-S V_{\Phi}$.

Further calculations show that 


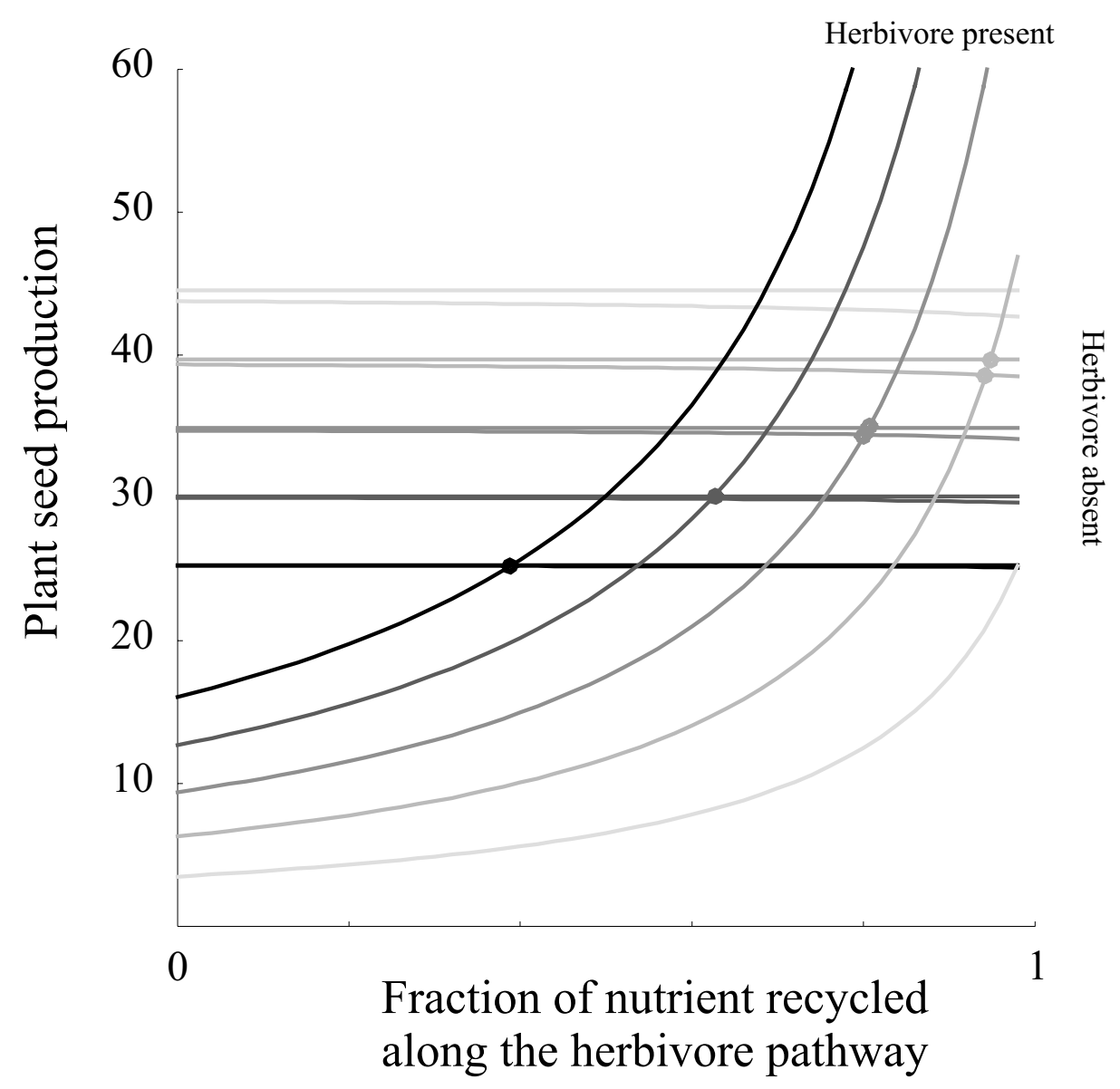

Figure A1: Plant seed production as a function of the fraction of nutrient recycled along the herbivore pathway, in the presence and in the absence of herbivores and for different scenarios of seed production: from light gray to black, $F=P^{*}, F=\frac{3}{4} P^{*}+\frac{1}{4} \Phi^{*}, F=\frac{1}{2} P^{*}+\frac{1}{2} \Phi^{*}, F=\frac{1}{4} P^{*}+\frac{3}{4} \Phi^{*}$, and $F=\Phi^{*}$. Two sets of curves (labeled in the figure) show seed production in the presence and absence of herbivores. For the latter case, we distinguish between seed production before (lower curve) and after (upper curve) evolutionary adaptation to this absence. Plant-herbivore interaction is mutualistic whenever plant seed production is higher in the herbivore's presence than in its absence. For each scenario, dots show the threshold condition for the interaction to be an ecological (lower dot) or an evolutionary mutualism (upper dot); the interaction is mutualistic to the right of the dots. In the example shown, the interaction can be mutualistic when seed production is proportional to primary production (black curves) but not when seed production proportional to biomass (lightest curves). This figure demonstrates that also intermediate scenarios of plant seed production can lead to mutualistic interactions. Parameters: $I=19.77$ kg.N.ha ${ }^{-1} \cdot \mathrm{yr}^{-1} ; l=4.57 \mathrm{yr}^{-1} ; k=8.47 \mathrm{yr}^{-1} ; d_{p}=0.57 \mathrm{yr}^{-1} ; \mathrm{v}_{p}=0.77 ;$ trade-off function: $c_{\min }=2.85 \mathrm{yr}^{-1} ; c_{\max }=7.27$ $\mathrm{yr}^{-1} ; u_{i}=0.58+3.64\left(c_{i}-c_{m i n}\right)^{0.55}$ ha.kg. $\mathrm{N}^{-1} \cdot \mathrm{yr}^{-1}$. 


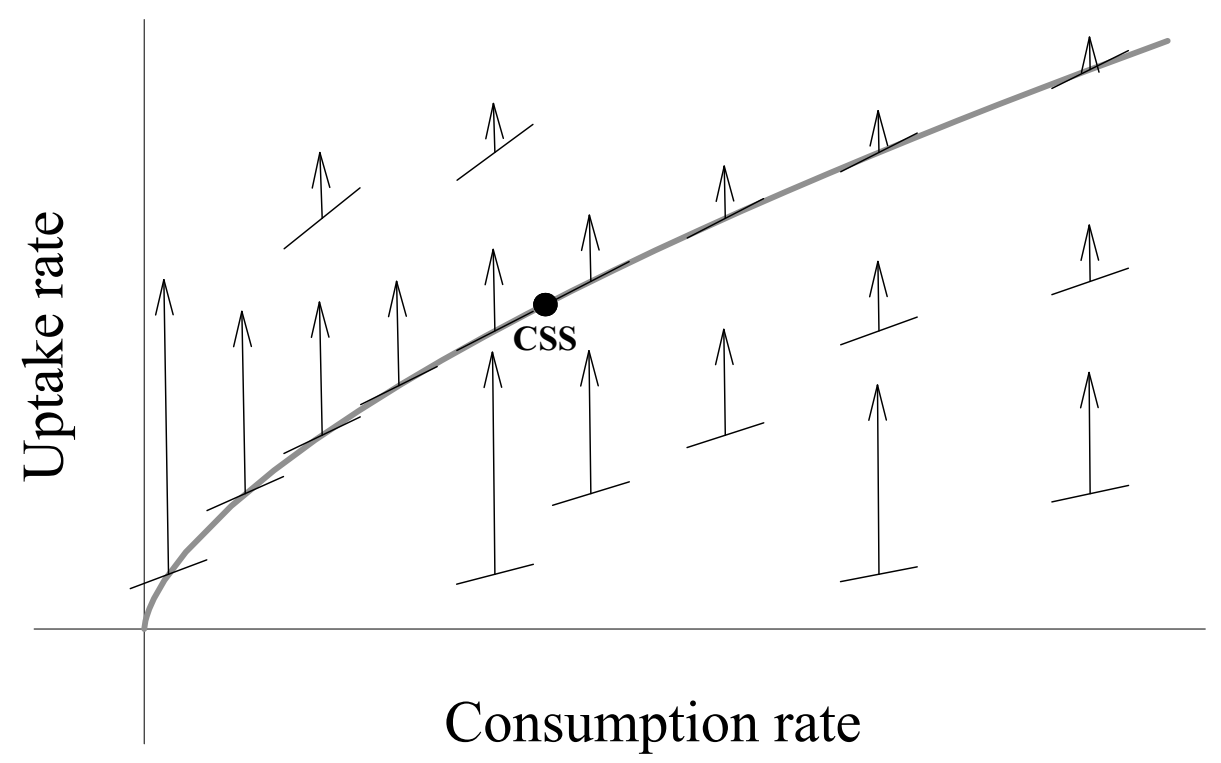

B

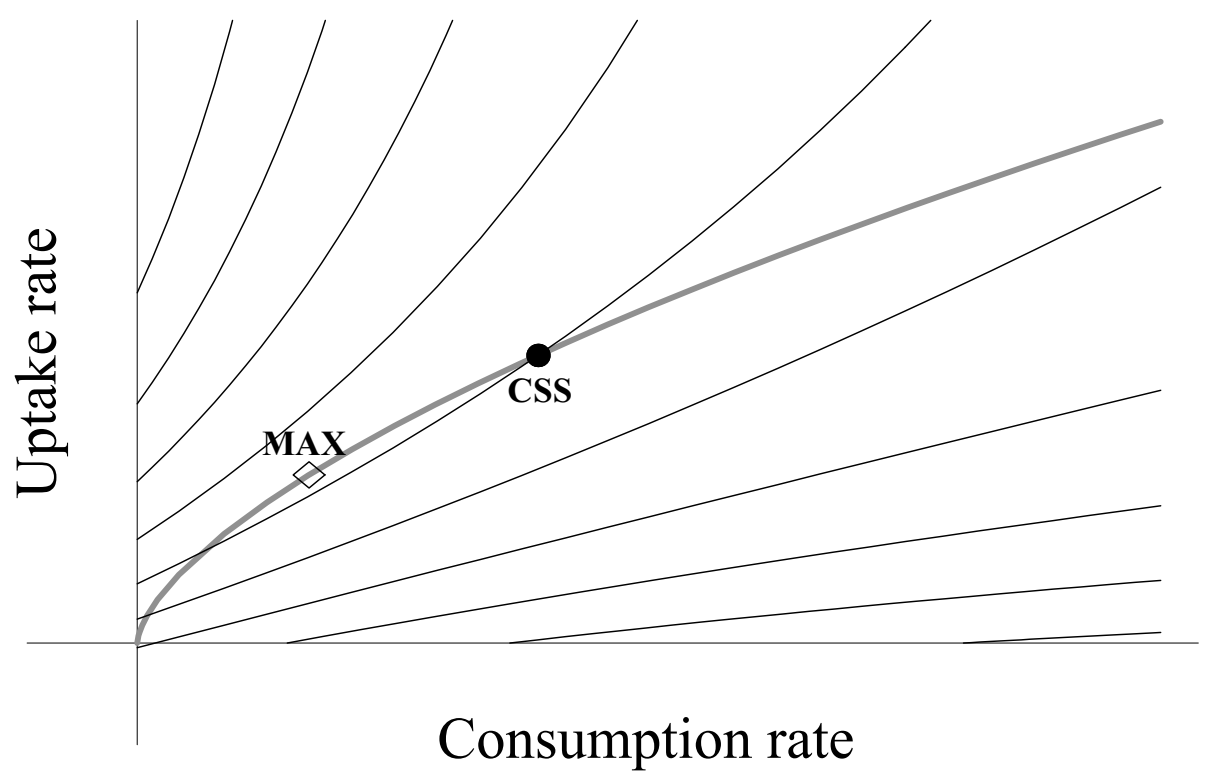

Figure A2: (A) Local invasion boundaries and direction of selection (arrows) in the plane of all possible plant strategies $(c, u)$. Each short line indicates the local boundary between invading (above) and noninvading strategies (below) for a resident strategy situated at the midpoint of the line. The continuously stable strategy (black dot) on the trade-off curve (solid line) is located where the invasion boundary is tangential to the trade-off curve. (B) Isolines of biomass in the plane of all possible plant strategies $(c, u)$. Biomass is zero for the bottom-right curve and increases towards the top-left. Biomass is maximized along the trade-off curve where the isolines of biomass and the trade-off curve are tangential (open diamond). The corresponding CSS is shown for comparison (black dot). Parameters: $I=28.11 \mathrm{~kg} \cdot \mathrm{N}^{-h^{-1}} \cdot \mathrm{yr}^{-}$ ${ }^{1} ; l=1.80 \mathrm{yr}^{-1} ; k=10.79 \mathrm{yr}^{-1} ; d_{p}=2.15 \mathrm{yr}^{-1} ; v_{p}=0.26 ; v_{h}=0.72$; trade-off function: $c_{\min }=2.54 \mathrm{yr}^{-1} ; c_{\max }=3.20 \mathrm{yr}^{-}$ ${ }^{1} ; u_{i}=0.17+0.17\left(c_{i}-c_{m i n}\right)^{0.63}$ ha.kg. $\mathrm{N}^{-1} \cdot \mathrm{yr}^{-1}$. 


$$
S V_{P}-S V_{\Phi}=\frac{u\left(v_{p} d_{p}+c\right)\left(u I-l\left(d_{p}+c\right)\right)}{(l+k)\left(v_{p} d_{p}+v_{h} c\right)\left(d_{p}+c\right)^{2}},
$$

which is positive under feasible biological conditions: a seed production that is proportional to biomass selects for higher defense levels than does a seed production that is proportional to primary production. This results from the fact that consumption has a greater negative impact on plant biomass than on primary production.

In summary, the slopes of the invasion boundaries in the different cases can be ranked as follows,

$$
S V_{P}>S V>S V_{\Phi}
$$

The slope of the local invasion boundary $V$ in the linear combination scenario is therefore intermediate between the slopes for the two extreme scenarios. Consequently, along a trade-off curve, the evolutionary outcome for the linear combination scenario will be intermediate between the evolutionary outcomes obtained in the two extreme scenarios.

Figure A1 shows that both ecological and evolutionary mutualisms are possible for cases that are intermediate between the two extreme scenarios of seed production. Conditions for mutualism become increasingly stringent when plant production is more determined by plant biomass than by primary production. 


\section{Appendix 2 Locating CSSs and Maximizing Strategies along the Trade-off Curve}

In a population consisting of one resident strategy, with consumption rate and nutrient uptake rate $\left(c_{r}, u_{r}\right)$, we analyze which other strategies are able to invade, when rare, into the resident population. In the plane $(c, u)$ of all consumption and uptake rate, for each resident strategy, we determine an invasion boundary, separating strategies that can invade from those that cannot. With $F_{m}$ denoting the seed production of a rare mutant with parameters $\left(c_{m}, u_{m}\right)$ when rare in the resident population, the slope of the invasion boundary is given by

$$
S V=\left[-\frac{\partial F_{m}}{\partial c_{m}} / \frac{\partial F_{m}}{\partial u_{m}}\right]_{\substack{c_{m}=c_{r} \\ u_{m}=u_{r}}} .
$$

Evolutionary outcomes can be determined graphically by plotting the trade-off curve together with the local invasion boundaries, as determined by their slope. Figure A2A shows the invasion boundaries (straight line segments) at some points $(c, u)$ of the set of strategies: each boundary separates the strategies that are capable and incapable of invading the resident strategy $\left(c_{r}, u_{r}\right)$ at the midpoint of the segment. The corresponding arrow shows the strength and direction of selection from the considered resident strategy. A CSS is located at a point along the trade-off curve where the invasion boundary is tangential to the trade-off curve. This condition is not sufficient for this point to be a CSS; more methodological details can be found elsewhere (de Mazancourt et al. 1998, C. de Mazancourt, M. Loreau, and U. Dieckmann, unpublished manuscript).

Similarly, the strategy maximizing plant biomass can be found by plotting the tradeoff curve together with the isolines of equilibrium biomass (Figure A2B). A maximum (or minimum) of plant biomass occurs along the trade-off curve where the biomass isolines are tangential to the trade-off curve. Analogously, the maximum of primary production occurs at the point where the trade-off curve is tangential to an isoline of primary production.

Comparing the slopes of the invasion boundaries with the isolines of biomass and primary production (Figure A2) therefore allows us to find the relative positions of the strategies that maximize biomass or primary production $\left(M A X_{P}\right.$ and $\left.M A X_{\Phi}\right)$ and of the evolutionary outcomes that result from plant adaptation under the two scenarios of plant seed production $\left(C S S_{P}\right.$ and $\left.C S S_{\Phi}\right)$. 


\section{References}

Aarssen, L. W., and D. R. Taylor. 1992. Fecundity allocation in herbaceous plants. Oikos 65:225-232.

Anstett, M. C., M. Hossaert-McKey, and F. Kjellberg. 1997. Figs and fig pollinators: evolutionary conflicts in a coevolved mutualism. Trends in Ecology and Evolution 12:94-99.

Bazely, D. R., and R. L. Jefferies. 1989. Leaf and shoot demography of an arctic stoloniferous grass, Pucinellia phryganodes, in response to grazing. Journal of Ecology 77:811-822.

Belsky, A. J. 1986. Does herbivory benefit plants? A review of the evidence. The American Naturalist 127:870-892.

Belsky, A. J., W. P. Carson, C. L. Jense, and G. A. Fox. 1993. Overcompensation by plants: herbivore optimization or red herring? Evolutionary Ecology 7:109-121.

Bender, E. A., T. J. Case, and M. E. Gilpin, 1984. Perturbation experiments in community ecology: theory and practice. Ecology 65:1-13.

Brown, J. H., P. A. Marquet, and M. L. Taper. 1993. Evolution of body size: consequences of an energetic definition of fitness. The American Naturalist 142:573-584.

Cargill, S. M., and R. L. Jefferies. 1984. The effects of grazing by lesser snow geese on the vegetation of a sub-arctic salt marsh. Journal of Applied Ecology 21:669-686.

Christiansen, F. B. 1991. On conditions for evolutionary stability for a continuously varying character. The American Naturalist 138:37-50.

de Mazancourt, C. 1998. Effets indirects des herbivores sur les producteurs primaires par recyclage des nutriments: Conséquences fonctionnelles et évolutives. Thèse de doctorat de l'université Paris 6, Université Pierre et Marie Curie, Paris, France. 279pp.

de Mazancourt, C., M. Loreau, and L. Abbadie. 1998. Grazing optimization and nutrient cycling: When do herbivores enhance plant production? Ecology 79: 2242-2252.

de Mazancourt, C., M. Loreau, and L. Abbadie. 1999. Grazing optimization and nutrient cycling: potential impact of large herbivores in a savanna ecosystem. Ecological Applications 9:784-797.

de Mazancourt, C., and M. Loreau. 2000a. Effect of herbivory and plant species replacement on primary production. The American Naturalist, 155 :735-754. 
de Mazancourt, C., and M. Loreau. 2000b. Grazing optimization, nutrient cycling, and spatial interaction of plant herbivore interactions: should a palatable plant evolve? Evolution, 54: 81-92.

Dieckmann, U. 1997. Can adaptive dynamics invade? Trends in Ecology and Evolution 12:128-131.

Dieckmann, U., R. Law. 1996. The dynamical theory of coevolution: a derivation from stochastic ecological processes. Journal of Mathematical Biology 34:579-612.

Douglas, A. E., and D. C. Smith. 1989. Are endosymbioses mutualistic? Trends in Ecology and Evolution 4:350-352.

Dyer, M. I., D. L. DeAngelis, and W. M. Post. 1986. A model of herbivore feedback on plant productivity. Mathematical Biosciences 79:171-184.

Eshel, I. 1983. Evolutionary and continuous stability. Journal of theoretical Biology 103:99-111.

Eshel, I., and U. Motro, 1981. Kin selection and strong stability of mutual help. Theoretical Population Biology 19:420-433.

Geritz, S. A. H., E. Kisdi, G. Meszéna, and J. A. J. Metz. 1998. Evolutionarily singular strategies and the adaptive growth and branching of the evolutionary tree. Evolutionary Ecology 12:35-57.

Herms, D. A., and W. J. Mattson. 1992. The dilemna of plants: to grow or defend. The Quarterly Review of Biology 67:283-335.

Hilbert, D. W., D. M. Swift, J. K. Detling, and M. I. Dyer. 1981. Relative growth rates and the grazing optimization hypothesis. Oecologia 51:14-18.

Huston, M. A., and D. L. DeAngelis. 1994. Competition and coexistence: the effects of resource transport and supply rates. The American Naturalist 144:954-977.

Järemo, J., J. Tuomi, P. Nilsson, T. Lennartsson. 1999. Plant adaptations to herbivory: mutualistic versus antagonistic coevolution. Oikos 84:313-320.

Krebs, C. J. 1985. Ecology. The experimental analysis of distribution and abundance New York, Harper \& Row. 800 pp.

Law, R., and U. Dieckmann. 1998. Symbiosis through exploitation and the merger of lineages in evolution. Proceedings of the Royal Society of London, Series B 265:1245-1253.

Lennartsson, T., P. Nilsson, and J. Tuomi. 1998. Induction of overcompensation in the field gentian, Gentianella campestris. Ecology 79:1061-1072. 
Lennartsson, T., J. Tuomi, and P. Nilsson. 1997. Evidence for an evolutionary history of overcompensation in the grassland biennal Gentianella campestris (Gentianaceae). The American Naturalist 149:1147-1155.

Loreau, M. 1995. Consumers as maximizers of matter and energy flow in ecosystems. The American Naturalist 145:22-42.

Loreau, M. 1996. Coexistence of multiple food chains in model ecosystems: interactions among community structure, ecosystem functioning, and nutrient dynamics. Mathematical Biosciences 134:153-188.

Lotka, A. J. 1922. Contribution to the energetics of evolution. Natural selection as a physical principle. Proceedings of the National Academy of Sciences of the United States of America 8:147-154.

Mathews, J. N. A. 1994. The benefits of overcompensation and herbivory: the difference between coping with herbivores and linking them. The American Naturalist 144:528-533.

Maynard Smith, J., and G. R. Price. 1973. The logic of animal conflict. Nature 246:1518.

Maynard Smith, J. 1982. Evolution and the theory of games. Cambridge University Press.

McNaughton, S. J. 1979. Grazing as an optimization process : grass-ungulate relationships in the Serengeti. The American Naturalist 113:691-703.

McNaughton, S. J. 1985. Ecology of a grazing ecosystem: the Serengeti. Ecological Monographs 55:259-294.

Meijden van der, E., M. Wijn, and H. J. Verkaar. 1988. Defense and regrowth, alternative plant strategies in the struggle against herbivores. Oikos 51:355-363.

Metz J. A. J., Geritz S. A. H., Meszéna G., Jacobs F. J. A., van Heerwaarden J. S. 1996. Adaptive Dynamics: A Geometrical Study of the Consequences of Nearly Faithful Reproduction. In: van Strien S. J., Verduyn Lunel S. M. (Eds.) Stochastic and Spatial Structures of Dynamical Systems, Proceedings of the Royal Dutch Academy of Science (KNAW Verhandelingen), North Holland, Amsterdam, pp.183-231.

Mole, S. 1994. Trade-offs and constraints in plant-herbivore defense theory: a lifehistory perspective. Oikos 71: 3-12.

Nilsson, P., J. Tuomi, and M. Aström. 1996a. Bud dormancy as a bet-hedging strategy. The American Naturalist 147:269-281.

Nilsson, P., J. Tuomi, and M. Åström. 1996b. Even repeated grazing may select for overcompensation. Ecology 77:1942-1946. 
Odum, H. T., and R. C. Pinkerton. 1955. Optimum efficiency or a maximum power output in physical and biological systems. American Scientist 43:331-343.

Owen, D. F., and R. G. Wiegert. 1981. Mutualism between grasses and grazers: an evolutionary hypothesis. Oikos 36:376-378.

Owen, D. F., and R. G. Wiegert. 1982. Grasses and grazers: is there a mutualism? Oikos 38:258-259.

Paige, K. N., and T. G. Whitham. 1987. Overcompensation in response to mammalian herbivory : the advantage of being eaten. The American Naturalist 129:407-416.

Paige, K.N. (1999) Regrowth following ungulate herbivory in Ipomopsis aggregata: geographic evidence for overcompensation. Oecologia 118: 316-323.

Petelle, M. 1982. More mutualisms between consumers and plants. Oikos 38:125-127.

Schoener, T. W. 1983. Field experiments on interspecific competition. The American Naturalist 122:240-285.

Silvertown, J. W. 1982. No evolved mutualism between grasses and grazers. Oikos 38:253-259.

Strauss, S.Y., A.A. Agrawal (1999) The ecology and evolution of plant tolerance to herbivory. Trends in Ecology and Evolution 14: 179-185.

Tilman, D. 1982. Resource Competition and Community Structure Princeton, Princeton University Press. 296 pp.

Tilman, D. 1988. Plant strategies and the dynamics and structure of plant communities. Princeton, Princeton University Press. 360 pp.

Tuomi, J., P. Nilsson, and M. Aström. 1994. Plant compensatory responses: bud dormancy as an adaptation to herbivory. Ecology 75:1429-1436.

Vail, S. G. 1992. Selection for overcompensatory plant responses to herbivory: a mechanism for the evolution of plant-herbivore mutualism. The American Naturalist 139:1-8. 